\title{
Benign sinus histiocytosis with massive lymphadenopathy: transient immunological defects in a child with mediastinal involvement
}

\author{
D. M. O. BECROFT, M. R. DIX, J. C. GIllmaN, BETH J. L. MacGREGOR, \\ AND R. L. SHAW
}

From the Princess Mary Hospital for Children and The Department of Pathology, University of Auckland School of Medicine, Auckland, New Zealand

SYNOPSIS A 16-month-old boy presented with cervical lymphadenopathy and a mediastinal mass causing tracheal displacement. Treatment of what at first was suspected to be a malignant neoplasm was limited to low-dose irradiation of the mediastinum and biopsy excision of the cervical lymph nodes. There has been no recurrence of disease in the subsequent four years.

The pathological features and clinical course correspond to a benign disease first described in 1969 in which there is massive proliferation of histiocytes in lymph node sinuses. No infectious cause was identified. Consistent but eventually reversible defects in lymphocyte response to phytohaemagglutinin and in augmentation of nitro-blue tetrazolium reduction by neutrophils during phagocytosis were demonstrated in the patient and in his monozygous twin. These defects in cellular immune function are believed to be important in the pathogenesis of the histiocytosis.

In 1969 Rosai and Dorfman introduced the term 'sinus histiocytosis with massive lymphadenopathy' to describe what they believed to be a newly recognized clinico-pathological entity which could be distinguished from 'malignant reticuloendotheliosis'. Their four cases, all children, had illnesses characterized by massive cervical lymphadenopathy, fever, leucocytosis, and hypergammaglobulinaemia. The course was benign, though lymphadenopathy was prolonged. Pathologically the enlarged nodes showed a dilatation of subcapsular and medullary sinuses by non-neoplastic histiocytes, in parts progressing to total effacement of the architecture. The histiocytes often had intracytoplasmic lymphocytes ('emperipolesis').

Recently Rosai and Dorfman (1972) reported on 30 further referred cases with similar histological appearances. In the majority the onset was in the first decade of life, the sex incidence was equal, and the distribution was world wide and multiracial. Extracervical lymph nodes and other tissues were involved in some cases. The authors suggested that, although the aetiology was unknown, the disease might be the expression of an abnormal immunological response.

Received for publication 9 May 1973.
In this report we will describe the demonstration of transient deficiencies in cellular immune functions in a case from New Zealand mentioned previously by Rosai and Dorfman (1972).

\section{Case Report}

A 16-month-old Caucasian child presented in March 1969 with a painless swelling of the left side of the neck for seven weeks. There had been mild pyrexia initially but no other symptoms. He appeared a healthy child of weight $11.4 \mathrm{~kg}$ and height $76 \mathrm{~cm}$. There was a firm, nodular mass $4 \mathrm{~cm}$ in diameter below the angle of the jaw on the left. The liver and spleen were just palpable. A chest radiograph (fig 1A) showed widening of the superior mediastinum bilaterally and a left-sided paravertebral mass extending down to the eleventh thoracic vertebra. The lower trachea was displaced to the right. The skeleton was normal. There was a mild irondeficiency anaemia. The white blood count was 9300/cmm (53\% neutrophils, 39\% lymphocytes, $3 \%$ eosinophils, $4 \%$ monocytes, and $1 \%$ Türk cells). The bone marrow was normal. The tuberculin test was negative.

A mass of enlarged left upper deep cervical lymph 


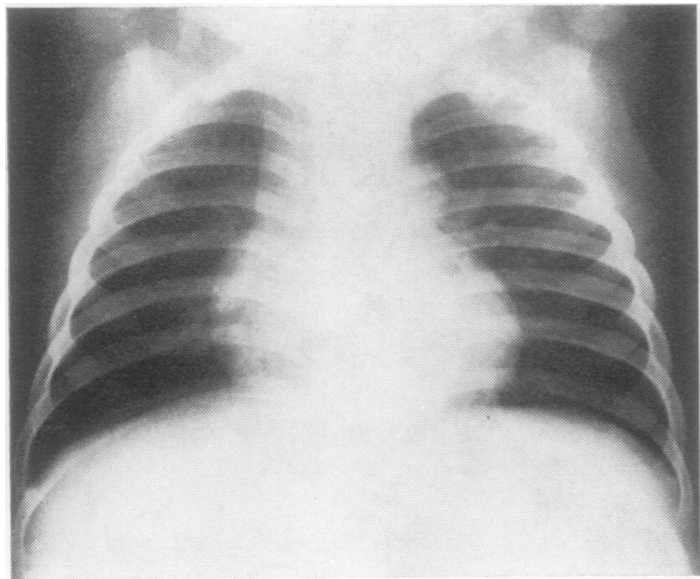

Fig. 1A The patient's chest radiograph at presentation aged 16 months showing widening of the mediastinum and a left paravertebral mass.

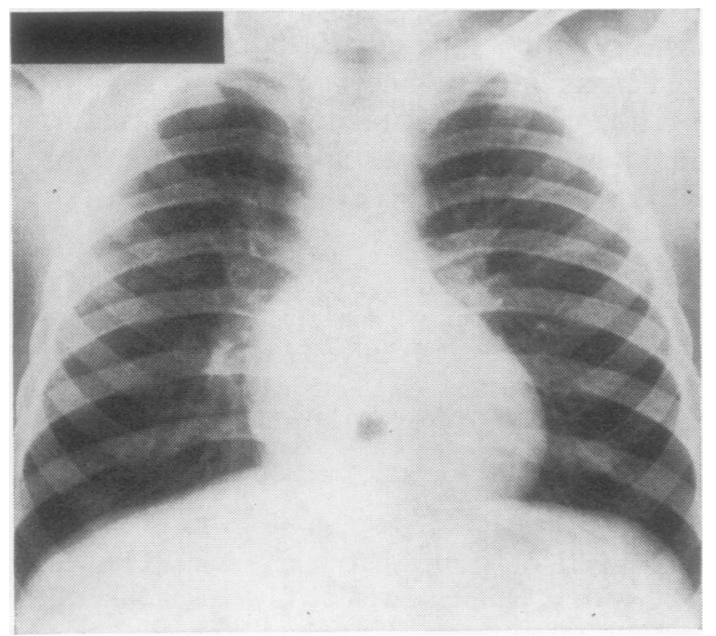

Fig 1B Normal appearances three and a half years later.

nodes was excised. Radiotherapy was directed to the mediastinal mass, but because the histological diagnosis was uncertain this was limited to a trial dose of 1000 rads. The mediastinal mass declined very slowly until after nine months the chest radiograph was normal. However, five months after radiotherapy was completed the left cervical lymphadenopathy recurred. The peripheral blood and bone marrow were normal. The enlarged left jugular, submaxillary, and posterior triangle lymph nodes were excised but no other treatment was given. Four years after his presentation he is well and there has been no further recurrence of lymphadenopathy or of mediastinal lesions (fig 1B).
An apparently identical twin has been observed over the same time and has shown no clinical, radiological, or haematological abnormalities. There is no other relevant family history.

\section{Pathology}

\section{G ROSS}

Each surgical specimen consisted of a mass of $\vec{\circ}$ adherent lymph nodes individually measuring up to $3 \mathrm{~cm}$ in diameter. The larger nodes had firm, paleyellow cut surfaces.

\section{MICROSCOPIC}

The smaller nodes and parts of the larger were normal or showed only non-specific sinus and follicular hyperplasia. Elsewhere there was a variable expansion of sinuses by large histiocytic cells which in the largest nodes had replaced all structures except for infrequent lymphoid follicles and remnants of medullary cords (fig 2). Most histiocytic cells were large and had abundant, palely eosinophilic homogeneous cytoplasm. Nuclei were centrally placed, round, and occasionally large and hyperchromatic, but mitoses were rare. In some areas histiocytes with densely eosinophilic cytoplasm were closely packed in an epithelial-like pattern (fig 3). Elsewhere, histiocytes were intermingled with lymphocytes, their cytoplasmic borders were scalloped, and the cytoplasm was often vacuolated. There was minimal erythrophagocytosis, but a striking feature in these areas was the presence of many intact lymphocytic nuclei within the histiocytic cytoplasm, the lymphocytes often ringing the centrally placed nucleus (fig 4). A few cells had foamy cytoplasm but only small amounts of sudanophilic lipid were demonstrated in frozen sections and no mucopolysaccharide was detected with Alcian blue. The cytoplasm did not stain with periodic-acid Schiff. There were no eosinophils, and neutrophils were confined to a few minute subcapsular foci of necrosis in the first specimen. The residual lymphoid tissue contained numerous plasma cells.

\section{Investigations into Aetiology and Pathogenesis}

\section{INFECTIONS}

No serum antibodies to rubella or toxoplasmosis were detected initially and no antibodies to Brucella were present two years later. No organisms were identified in histological sections of the lymph nodes using Gram, periodic-acid-Schiff, and Ziehl-Neelsen stains, nor in sections stained with rhodamineauramine for fluorescing mycobacteria. No bacteria, 


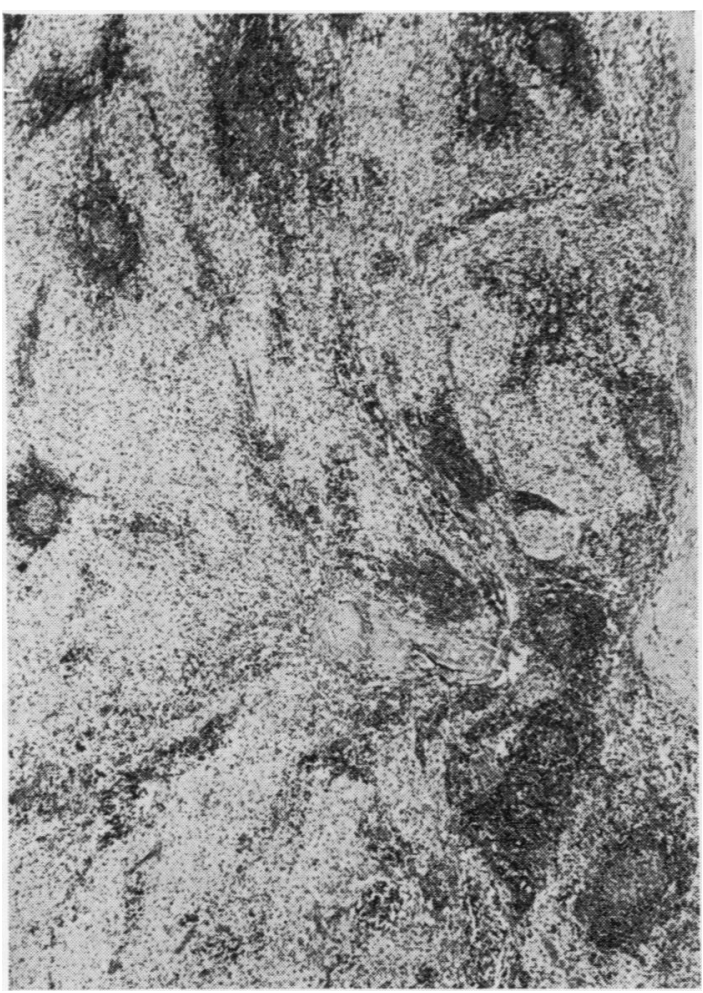

Fig 2 A lymph node at low magnification showing extensive replacement of normal structure by palelystaining cells. $A$ few lymphoid follicles persist. $H$ and $E$ $(\times 70)$.

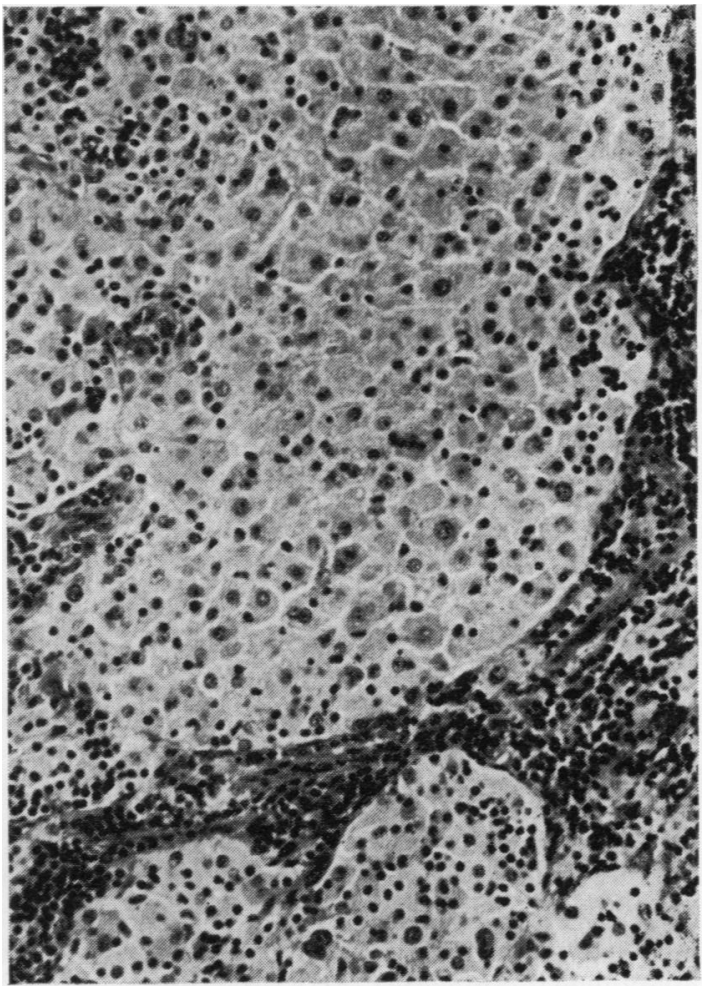

Fig 3 Histiocytes filling a distended lymph node sinus. Some nuclear pleomorphism and an epithelial-like appearance are shown $H$ and $E(\times 400)$.

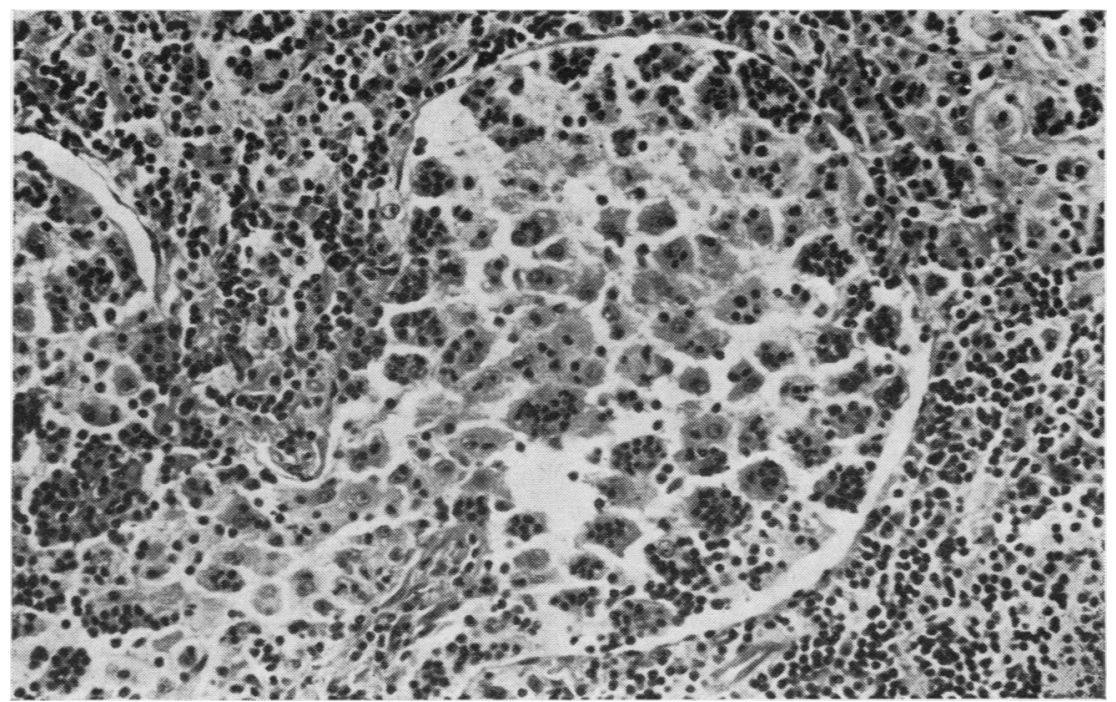

Fig 4 A distended lymph node sinus in which many histiocytes contain phagocytosed lymphocytes (emperipolesis), $H$ and $E(\times 400)$. 
viruses, or other specific cytoplasmic structures were detected by electron microscopy of formalin-fixed material from the second specimen (Rosai, 1970). Tissue from both biopsy specimens was cultured for mycobacteria with negative results. No aerobic or anaerobic bacteria or fungi were isolated from the second specimen after prolonged culture. Attempts to establish a tissue culture from the second specimen were unsuccessful.

\section{HUMORAL IMMUNITY}

The patient's serum immunoglobulin levels estimated by radial diffusion during his first hospital admission were: IgG $12.5 \mathrm{mg} / \mathrm{ml}, \operatorname{IgM} 2.0 \mathrm{mg} / \mathrm{ml}$, and IgA 1.4 $\mathrm{mg} / \mathrm{ml}$. Three years later serum levels were: $I g G$ $9.9 \mathrm{mg} / \mathrm{ml}, \operatorname{IgM} 0.9 \mathrm{mg} / \mathrm{ml}$, and IgA $1.2 \mathrm{mg} / \mathrm{ml}$. The serum $\mathrm{B}_{\mathbf{1}}$-A globulin ( $\mathrm{C} 3$ complement component) also estimated by radial diffusion was normal at $102 \mathrm{mg} / 100 \mathrm{ml}$. The patient's serum generated a normal chemotactic stimulus when tested by methods given below.

\section{CELLULAR IMMUNITY}

Whenever possible studies were made simultaneously on cells from the patient and his twin. The twins were found to be identical for all blood group, serum, and histocompatibility antigens tested, giving an estimated probability $(P)$ of dizygosity of $<0.003$.

\section{TESTS OF PHAGOCYTIC FUNCTION}

In September 1972 the patient's neutrophils had normal random mobility when studied by the method of Harris (1953).

Chemotaxis was studied in a modified Boyden chamber using methods based on those of DeMeo and Andersen (1972). The chemotactic stimulus was generated by incubation of Zymosan with either homologous or control sera. The chemotactic response was assessed by counting the neutrophils traversing a standard area of a $3 \mu$ pore-size Millipore filter. These studies, in September 1972, showed a normal response by the patient's cells and a normal stimulus generated by his serum.

Quantitative nitro-blue tetrazolium (NBT) tests were performed using the method of Baehner and Nathan (1968) in which the intracellular reduction of NBT by peripheral blood phagocytes is measured spectrophotometrically, with and without phagocytic stimulation by exposure to latex particles. The 'resting' and 'stimulated' levels expressed as optical densities and the differences ( $\Delta \mathrm{O} \mathrm{D})$ obtained in studies on the patient and his twin between November 1971 and September 1972 are presented in figure 5. The time relationship with the results of other studies are indicated in the table. The resting levels were normal or near normal on all

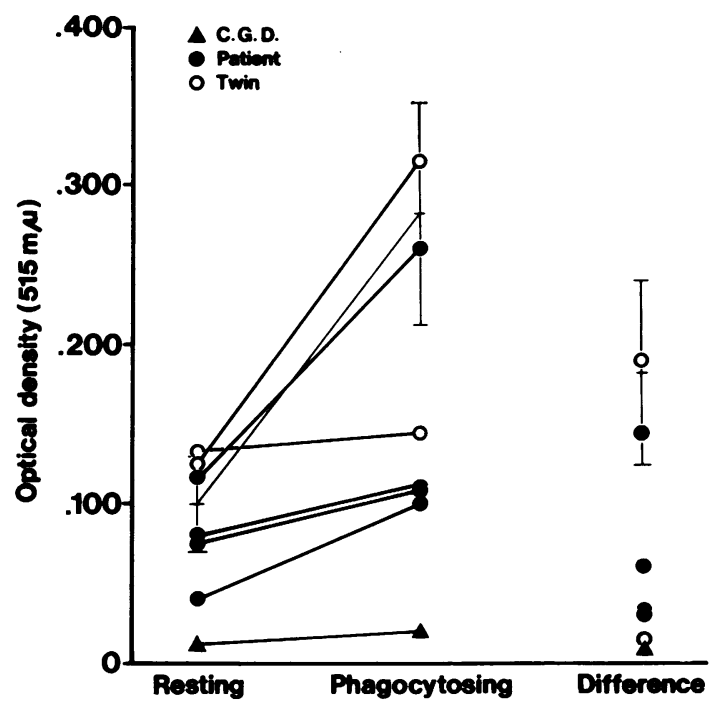

Fig 5 Quantitative NBT tests on leucocytes. Resting and stimulated levels for individual tests are linked and the difference $(\triangle O D)$ is shown separately. Vertical columns indicate the mean levels $\pm 2 S D$ for 11 normal controls studied concurrently. The means of five tests on two children with chronic granulomatous disease (CGD) are also shown.

occasions but the patient's cells on the first three occasions and the twin's cells on one occasion failed to show normal stimulation during observed phagocytosis of latex. The difference between the responses in the twins and in controls is significant 3 $(P<0.001)$. Further studies six months later gave an intermediate level of response in the patient and a normal response in his twin and after ao further three months a normal response was obtained with the patient's cells. Levels of NBT reduction were also estimated by the cytochemical method of Hicks and Bennett (1971) which differs from the or above in that cyanide-sensitive metabolic pathways $N$ are not inhibited and reduction is assessed by aN cytochemical scoring of neutrophils, either 'resting' $\omega$ or after latex stimulation. Resting scores in both children were significantly higher than those ob- $\frac{0}{0}$ tained in 38 control subjects $(\mathrm{P}<0.0005)$ and their@ mother, while the augmentation during latex stimulation was significantly less $(P<0.0025$ for patient, $<0.01$ for twin) than in eight controls.

The bactericidal capacity of peripheral blood $\frac{?}{\mathbb{D}}$ phagocytes against the Oxford staphylococcus was studied by the method of Quie, White, Holmes, and Good (1967) and the results given in the table areo within normal limits. 


\begin{tabular}{|c|c|c|c|c|c|c|c|}
\hline \multirow[t]{3}{*}{ Subject } & \multirow[t]{3}{*}{ Date } & \multirow[t]{3}{*}{ PHA Response ${ }^{1}$} & \multicolumn{4}{|l|}{ NBT Tests } & \multirow{3}{*}{$\begin{array}{l}\text { Bactericidal } \\
\text { Tests }\end{array}$} \\
\hline & & & \multirow{2}{*}{$\frac{\text { Spectrophotometric }}{O . D .^{3}}$} & \multicolumn{3}{|c|}{ Cytochemical Score } & \\
\hline & & & & Resting & Stimuated & Difference & \\
\hline Patient & $\begin{array}{ll}\text { Nov } 1971 \\
\text { Dec } 1971 \\
\text { Feb } 1972 \\
\text { June } 1972 \\
\text { July } 1972 \\
\text { Sept } 1972\end{array}$ & $\begin{array}{cc}5.0 & (74.6)^{2} \\
0.6 & 5 \cdot 1) \\
7.0 & (37.6) \\
& \\
59.5 & (106.6) \\
88.1 & (65.7)\end{array}$ & $\begin{array}{l}0.030 \\
0.033 \\
0.060 \\
0.144\end{array}$ & $\begin{array}{l}33 \\
16\end{array}$ & $\begin{array}{l}31 \\
23\end{array}$ & $\begin{array}{l}-2 \\
+7\end{array}$ & $94 \%$ \\
\hline Twin & $\begin{array}{ll}\text { Dec } & 1971 \\
\text { Feb } & 1972 \\
\text { June } & 1972 \\
\text { July } & 1972\end{array}$ & $\begin{array}{lr}0.9 & (5 \cdot 1) \\
4 \cdot 8 & (37 \cdot 6) \\
111(106 \cdot 6)\end{array}$ & $\begin{array}{l}0.014 \\
0.190\end{array}$ & 21 & 25 & +4 & $88 \%$ \\
\hline Mother & June 1972 & & & 7 & 57 & +50 & \\
\hline $\begin{array}{l}\text { Controls } \\
\quad(\text { mean } \pm \text { SD })\end{array}$ & & & $\begin{array}{l}0.182 \pm 0.029 \\
(n=11)\end{array}$ & $\begin{array}{l}6 \cdot 3 \pm 2 \cdot 5 \\
(n=38)\end{array}$ & $\begin{array}{l}59 \pm 11 \\
(n=8)\end{array}$ & $\begin{array}{l}53 \pm 15 \\
(n=8)\end{array}$ & \\
\hline
\end{tabular}

Table Tests on blood leucocytes

${ }^{1}$ Tritiated thymidine uptake (cpm per $10^{3}$ lymphocytes). Unstimulated levels $<1.0$ in all experiments.

${ }^{2}$ Concurrent control values in parentheses

'Difference between resting and stimulated levels

'Percentage of bacteria killed in two hours.

TESTS OF LYMPHOCYTE RESPONSIVENESS

The response of blood lymphocytes to phytohaemagglutinin (PHA) stimulation was assessed by a method based on that of Fitzgerald (1972). Lymphocytes from whole plasma, or after partial separation from other leucocytes on a nylon column, were exposed to a range of concentrations of PHA and the response was measured by the uptake of tritiated thymidine. The results given in the table are of the maximal stimulation obtained, this usually occurring at PHA concentrations of either 20 or $200 \mu \mathrm{g} / \mathrm{ml}$. The results largely parallel those of the NBT test, with deficient responses from specimens obtained from the patient and his twin before February 1971, while more recent studies have given normal results.

\section{Discussion}

This child presented with cervical lymphadenopathy and radiological findings which are assumed to have been due to massive enlargement of mediastinal lymph nodes by the same pathological process. Because of initial uncertainty as to the diagnosis treatment was limited to biopsy-excision of cervical lymph nodes and low-dose irradiation to the mediastinum. Excision of a later recurrence was also considered incomplete. Therefore the subsequent course, without further recurrence, is consistent with an intrinsically benign disease and corresponds with that of other cases described by Rosai and Dorfman (1972). The close histological resemblance has been confirmed (Rosai, 1970) and there seems little doubt that this is the same clinico-pathological entity. The cervical lymphadenopathy was less severe than in many other cases, possibly because of early palliative surgery. This case was one of nine described by Rosai and Dorfman (1972) with perihilar or mediastinal masses, out of 21 in which chest radiographs were taken. One other had a paravertebral mass.

The paravertebral mass in our patient caused strong suspicion initially of a primary abdominal malignancy and of neuroblastoma in particular. Neuroblastoma, other embryonic tumours, the common malignant lymphomas, and the storage diseases were excluded promptly by histological examination of biopsy material. The identification of the cells expanding the lymph nodes was complicated by the epithelial-like appearance of some areas, but once their histiocytic nature was appreciated the major diagnostic problem lay in the exclusion of the generalized and usually lethal forms of systemic histiocytic proliferation or 'reticuloendothelioses' (Rappaport, 1966). Histiocytic medullary reticulosis and other malignant histiocytoses, histiocytosis ' $\mathrm{X}$ ', and variously named familial forms of histiocytic or lymphohistiocytic proliferation (Berard, Cooper, Freireich, and Rabson, 1966; Miller, 1966) appeared unlikely on clinical and pathological grounds.

The benign course, the initial fever and hyperimmunoglobulinaemia, and the leucocytosis noted in other cases are consistent with an infectious aetiology. Both patient and twin when apparently well had significantly elevated 'resting' levels of NBT reduction as assessed by the cytochemical method which is being applied widely as a test 
indicative of active bacterial infection (Lancet, 1971). However, the distribution of the lymphadenopathy could not be accounted for by a single inflammatory focus nor was such a focus demonstrated. Other investigations excluded infections by several microorganisms likely to cause chronic lymphadenopathy.

Infection remains the most likely primary aetiology but a histiocytic reaction of this degree, without abscess or granuloma formation, would be an exceptional response except where cellular immune reactions were impaired. Associated immune defects have been offered as an explanation for extreme histiocytic reactions produced by identifiable infections such as rubella (Claman, Suvatte, Githens, and Hathaway, 1970) and atypical mycobacteria (Clinico-pathological Conference, 1970). There may be striking histiocytic proliferation in some children who have severe congenital defects in T-lymphocyte-mediated cellular immunity in association with thymic dysplasia (Becroft and Douglas, 1968). Widespread proliferation of pigmented lipid-containing histiocytes occurs in chronic granulomatous disease in which a metabolic defect in phagocytes leads to defective intracellular killing of certain bacteria (Carson, Chadwick, Brubaker, Cleland, and Landing, 1965). Thus, histiocytic proliferation may be the result of diminished killing of phagocytosed microorganisms due either to intrinsic cellular defects or to the nature of the organism. Progression to granuloma formation would be usual but this progression would tend to be inhibited by any associated defect in lymphocyte-mediated delayed-type hypersensitivity reactions.

Therefore there may be considerable pathogenetic significance in the finding in our patient's leucocytes of a combination of defective lymphocyte response to PHA and diminished augmentation of NBT reduction during phagocytosis. Although these results were obtained when he appeared free of disease, each defect was confirmed on three separate occasions over an eight-month period when concurrent control values were generally satisfactory. The defects were transient and therefore are presumed to be acquired rather than congenital. A defective PHA response is widely accepted as indicating a defect in lymphocyte-mediated cellular immunity. It is less certain whether the failure of augmentation of the NBT response over normal or elevated resting levels has the same functional significance as the defects in both resting and stimulated levels observed in chronic granulomatous disease (Baehner and Nathan 1968). Similar transient defects in augmentation of the NBT response in two recently described cases were associated with a transient increase in susceptibility to bacterial infection (Douglas, Lahav, and Fudenberg, 1970; Kretschmer, López-Osuna, and Valenzuela, 1972). In one case a bactericidal defect was also demonstrated in vitro (Douglas et al, 1970) whereas our patient's leucocytes had normal bactericidal activity against the single organism tested. A. child described recently (McCracken, Weinberg, and Carlin, 1972) resembled our patient in showing widespread histiocytic proliferation and acquired defects in both lymphocyte reactivity and in augmentation of the NBT response, but the defects were progressive and the child died of granulomatous lung disease.

The interpretation of the results in our patient $\hat{N}_{\Omega}$ was further complicated by the similar findings in the apparently unaffected monozygous twin. There $\vec{\circ}$ was less repetition of abnormal results in the twin, $\omega$ but if these are accepted as valid then alternative 음 possibilities are that the twin had a subclinical form $\rightarrow$ of the disease, that both had an inherited but $气$ transient immune defect which predisposed to a disease precipitated in the patient by some additional $\vec{\theta}$ factor, or that the defects and the disease were $\omega$ unrelated. In our opinion there is strong likelihood that the defects were of significance in the pathogenesis of the histiocytic reaction, but the primary aetiology and relative contribution of genetic and environmental factors remain in doubt.

\section{References}

Baehner, R. L., and Nathan, D. G. (1968). Quantitative nitroblue tetrazolium test in chronic granulomatous disease. New Engl. J. ? Med., 278, 971-976.

Becroft, D. M. O., and Douglas, R. (1968). Thymic alymphoplasia. monoclonal gammopathy, and Pneumocystis carinii pneumonia in an infant. Arch. Dis. Childh., 43, 444-450.

Berard, C. W., Cooper, R. A., Freireich, E. J., and Rabson, A. S. 3 . (1966). Disseminated histiocytosis associated with atypical lymphoid cells (lymphohistiocytosis). Cancer (Philad.), 19, 윽 1429-1437.

Carson, M. J., Chadwick, D. L., Brubaker, C. A., Cleland, R. S., O and Landing, B. H. (1965). Thirteen boys with progressive septic granulomatosis. Pediatrics, 35, 405-412.

Claman, H. N., Suvatte, V., Githens, J. H., and Hathaway, W. E. 음 (1970). Histiocytic reaction in dygammaglobulinemia and congenital rubella. Pediatrics, 46, 89-96.

Clinico-pathological Conference (1970). Histiocytosis and infection $\mathcal{G}$ with atypical mycobacteria. Amer. J. Med., 49, 830-840.

DeMeo, A. N., and Andersen, B. R. (1972). Defective chemotaxis associated with a serum inhibitor in cirrhotic patients. New $\mathrm{W}$ Engl. J. Med., 286, 735-740.

Douglas, S. D., Lahav, M., and Fudenberg, H. H. (1970). A reversible neutrophil bactericidal defect associated with a mixed cryo-e globulin. Amer. J. Med., 49, 274-280.

Fitzgerald, M. G. (1972). A satisfactory quantitative test of lympho-思 cyte response to phytohaemagglutinin for the definition of ${ }^{+}$ normal control values and recognition of immunological $\square$ defects. J. clin. Path., 25, 163-168.

Harris, H. (1953). Chemotaxis of granulocytes. J. Path. Bact., 66, $\frac{\text { (D) }}{\stackrel{P}{(}}$ $135-146$.

Hicks, R. G., and Bennett, J. M. (1971). An improved cytochemical $\frac{\vec{D}}{\mathrm{Q}}$ method for nitroblue tetra-zolium reduction by neutrophils. Amer. J. med. Technol., 37, 226-229.

Kretschmer, R. R., López-Osuna, M., and Valenzuela, R. H. (1972). Reversible neutrophil defect in atazia telangectasia. Pediatrics, $\bigcirc$ 50, $147-150$. 
Lancet (1971). Editorial. Nitroblue tetrazolium, a routine test? Lancet, 2, 909-910.

McCracken, G. H., Weinberg, A. G., and Carlin, M. E. (1972). Granulomatous lung disease with progressive deterioration of phagocytic function. J. Pediat., 81, 267-274.

Miller, D. R. (1966). Familial reticuloendotheliosis: concurrence of disease in five siblings. Pediatrics, 38, 986-995.

Quie, P. G., White, J. G., Holmes, B., and Good, R. A. (1967). In vitro bactericidal capacity of human polymorphonuclaer leukocytes: diminished activity in chronic granulomatous

disease of childhood. J. clin. Invest., 46, 668-679.

Rappaport, H. (1966). Tumors of the Hematopoietic System (Atlas of Tumor Pathology, Sect. 111, Fasc. 8). Armed Forces Institute of Pathology, Washington, D.C.

Rosai, J. (1970). Personal communication.

Rosai, J., and Dorfman, R. F. (1969). Sinus histiocytosis with massive lymphadenopathy. Arch. Path., 87, 63-70.

Rosai, J., and Dorfman, R. F. (1972). Sinus histiocytosis with massive lymphadenopathy: a pseudolymphomatous benign disorder. Cancer (Philad.), 30, 1174-1188. 